\title{
COPD audit in primary care
}

\author{
Ashok Deshpande, Janet Caira
}

\section{Introduction:}

Chronic Obstructive Pulmonary Disease (COPD) is a common cause of consultations in Primary Care and accounts for as many as 1 in 8 medical admissions. ${ }^{1}$ Currently, nearly 600,000 patients in the UK suffer from COPD. The main cause of COPD is tobacco smoking. ${ }^{2}$ Other risk factors being intense or chronic exposure to occupational dust or chemicals, and exposure to heating fuels. ${ }^{2}$ Patients with COPD suffer from chronic symptoms such as breathlessness, cough on exertion and difficulty in carrying out day to day normal activities. The aims of this audit were to establish accurate diagnosis of COPD, to evaluate appropriate ongoing therapy e.g. to evaluate the impact of reduction in inhaled corticosteriods on symptoms or increase in usage of inhaled anticholinergics, and last but not least, to encourage patients to stop smoking, thereby promoting quality of care.

\section{Methods}

This study was undertaken at Wood Lane Surgery, Hornchurch. This is a two-doctor practice with a practice population of 4,700 . The practice nurse has been trained to Diploma level at the National Asthma and Respiratory Training Centre (NARTC). The study proposed three audit cycles with interval of 6-12 months from August 1998. The Surgery initiated contacts to COPD/Asthma patients over the age of 40 years who had used preventative therapy in the preceding 12 months. The initial search of the practice population revealed 82 patients who were potentially suffering from COPD (43-86 years). The practice had the support of a Specialist Nurse from 'COPD Response'. All these patients were subjected to spirometry and reversibility tests for confirmation of their diagnosis with pre and post bronchodilator spirometry results. Those with ratio of Forced
Expiratory Volume in 1 second $\left(\mathrm{FEV}_{1}\right)$ to Forced Vital Capacity (FVC) below $70 \%$ confirmed the diagnosis. ${ }^{3}$ A post-bronchodilator increase in $\mathrm{FEV}_{1}$ of less than $200 \mathrm{mls}$ is more suggestive of COPD than asthma. The diagnosis of Chronic Obstructive Pulmonary Disease (COPD) was confirmed in 47 patients. The age distribution of these 47 patients has been shown in Figure 1. A total of $74.4 \%$ of our patients (total 35) were in the age group from 50 to 79 years. Only seven patients $(14.8 \%)$ were between the age of 50 to 59 years. Of these 47 patients, 27 were males $(57.4 \%)$ and the remaining 20 were females $(42.5 \%)$. The post-bronchodilator $\mathrm{FEV}_{1}$, as a percentage of the predicted $\mathrm{FEV}_{1}$, is used to classify the severity of COPD. (Mild:60-80\% predicted $\mathrm{FEV}_{1}$, moderate:40-59\% and severe below 40\%). Graph 2 represents severity of the disease as per number of patients. A quarter of our patients $(25.5 \%)$ had mild disease while $53 \%$ of our patients $(n=25)$ were suffering from moderate COPD. The remaining 21\% $(n=10)$ had severe COPD. All these patients were given the St George's Respiratory Impact Questionnaire (SGRIQ) (only the impact part) to complete. This helped to evaluate their symptom scores and quality of life. Smoking data was also collected from SGRIQ. This data was validated by carbon monoxide (CO) monitoring. The carbon monoxide monitor was unfortunately not available for the earlier audit cycles but was used during the $3 \mathrm{rd}$ audit in January 2001.

Current medications were reviewed in each audit cycle and modified accordingly to the guidelines of the British Thoracic Society (BTS). Follow-ups for these patients were arranged for subsequent audit cycles. During the study period of nearly three years, there was some change of COPD patients, some had left the practice area, some had died and new patients joined the practice.
Figure 1. Age distribution of COPD patients: January 1999

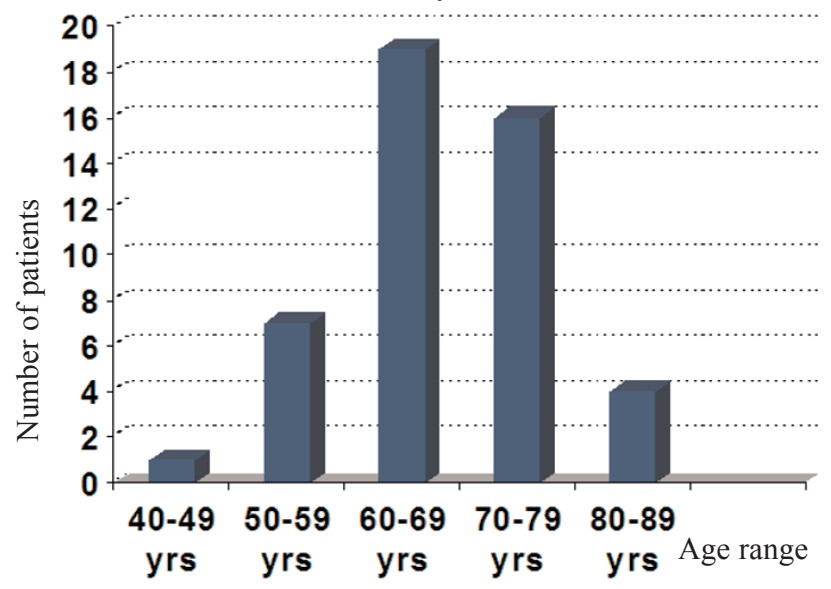

Figure 2. Severity of disease January 1999

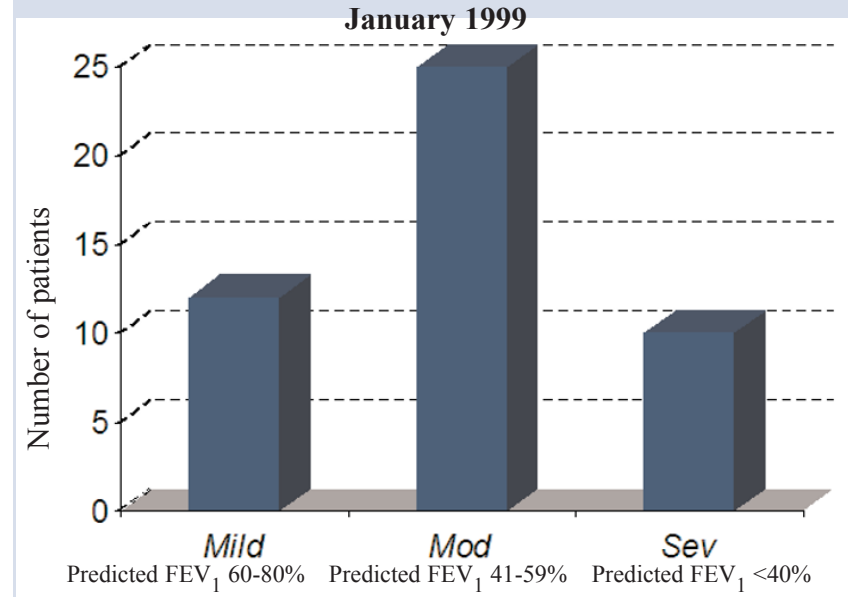


Results

The outcome of medication, quality of life questionnaire (SGRIQ) and smoking status of patients were compared in subsequent audit cycles. The total number of COPD patients reviewed was 37 in March 2000 and in January 2001. The reasons for this reduction were that some patients left the practice and others died during the audit cycles. Table 1 summarises the results of usage of B2 agonists on a regular basis and as per necessary (prn) basis, and use of anticholenergic drugs.

In January 1999 48\% (n=23) of COPD patients were using B2 agonists on a regular basis and this increased to $97 \%(n=36)$ in March 2000 and $92 \%(n=34)$ in January 2001. A total of $21 \%(n=10)$ of patients were on inhaled anticholenergic in January 1999, which subsequently increased to $51 \%$ in January 2001 $(n=19)$. Table 2 presents the pattern of inhaled corticosteriods over the period of three years. The percentage of patients on inhaled corticosteriods reduced from $70 \%(\mathrm{n}=34)$ to $53 \%(\mathrm{n}=21)$ in January 1999 to January 2001 respectively. There was a marginal increase from March 2000 (47\%) as new patients with COPD joined the practice and these were already on inhaled corticosteriods. Table 2 also emphasises the comparative reduction of patients who were on high doses of inhaled corticosteriods $(800 \mathrm{mcg}$ daily). Some $44 \%(n=15)$ of patients were on high doses of inhaled corticosteriods in January 1999 while only $8 \%(n=3)$ in January 2001.

The results of smoking cessation are represented in Figure 3. In January 1999, 50\% of COPD patients were smoking $(n=26)$ and this reduced to $24 \%(n=9)$ in January 2001. This data has been confirmed by carbon monoxide estimation (CO) in January 2001. $67 \%(n=20)$ of COPD patients showed traces of carbon monoxide between $0-3 \%, 13 \%$ of the patients declined the test. Figure 4 represents the analysis of impact part of quality of life questionnaires (SGRIQ). The percentage of patients feeling better increased from $35 \%(n=17)$ to $57 \%(n=21)$ from January 1999 to January 2001 respectively.
Table 1. Audit outcomes; medication

$\begin{array}{lrrrr} & \mathbf{1 9 9 8} & \mathbf{1 9 9 9} & \mathbf{2 0 0 0} & \mathbf{2 0 0 1} \\ \text { \% B2 agonist prn } & 53 & 25 & 0 & 0 \\ \text { \% B2 agonist regularly } & 30 & 23 & 36 & 34 \\ \text { \% anticholinergic } & 17 & 10 & 18 & 19 \\ \text { Number of patients } & 82 & 47 & 37 & 37\end{array}$

Table 2. Audit outcomes; Corticosteroid therapy

$\begin{array}{lrrrr} & 1998 & 1999 & 2000 & 2001 \\ & & & & \\ \%>800 \mathrm{mcg} \text { inhaled corticosteroids } & 50 & 44 & 10 & 14 \\ \%<800 \text { mcg inhaled corticosteroids } & 50 & 56 & 90 & 86 \\ \text { Total patients on cortcosteroids } & 50 & 34 & 19 & 21\end{array}$

\section{Discussion}

Airway obstruction in COPD is irreversible, bronchodilators are still the mainstay of symptomatic drug management. In addition to dilating airways, these drugs can alleviate breathlessness by reducing pulmonary hyperinflation. ${ }^{4}$ A systematic review of 13 short randomised placebo controlled studies found that regular use of a short-acting inhaled B2 agonist increased $\mathrm{FEV}_{1}$ and post-bronchodilator peak expiratory flow (PFR) ${ }^{5}$ The British Thoracic Society's (BTS) guidelines suggest that regular usage of B2 agonists control the symptoms and thereby improve quality of life. The current audit has shown that the regular use of $\mathrm{B} 2$ agonists by COPD patients has increased from (48\%) in January 1999 to (97\%) in March 2000. As the new population of COPD patients who were on B2 agonist on an 'as required' basis (prn) joined the practice, this figure again has declined to $92 \%$ in January 2001. Regular use of inhaled anticholenergic drugs such as Iptrapropium have increased from $2 \%$ to $57 \%$ during this audit period.

The place of inhaled corticosteroids in COPD is controversial. Several longer term randomised controlled trials have found that regular use of high doses of inhaled corticosteriods (Fluticasone $1000 \mathrm{mcg}$ daily and Budesonide $800 \mathrm{mcg}$ daily) have no effect on decline in lung function in the long term. ${ }^{6,7}$ However,
Figure 3. Audit Outcome: Smoking status

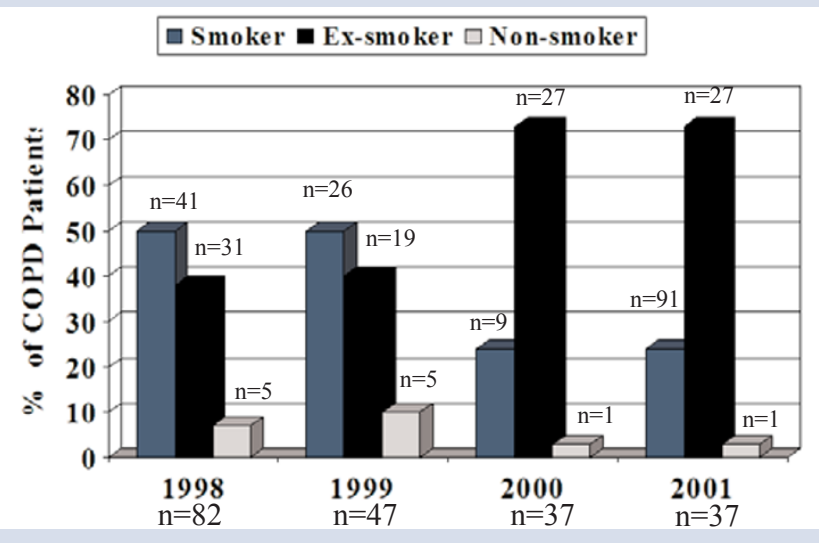

Figure 4. Audit Outcome: SGRQ (Impact) Assessment

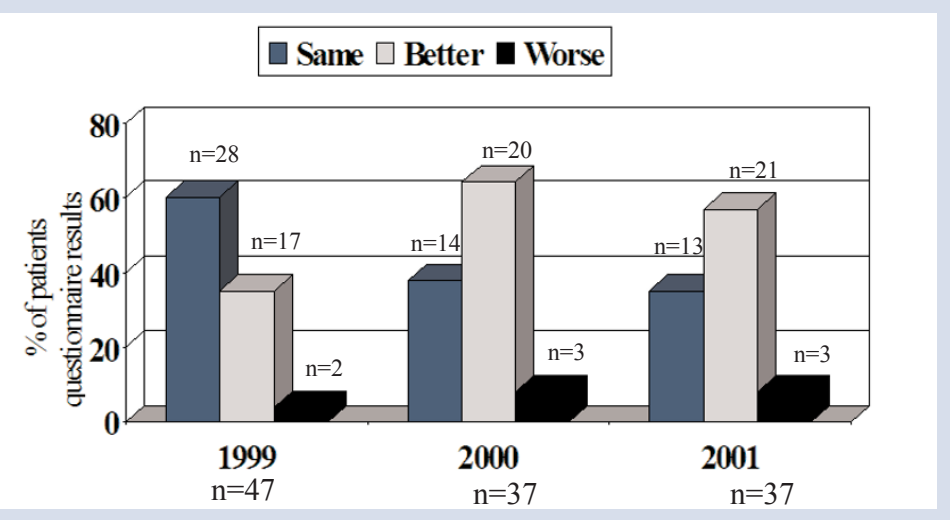


the ISOLDE study found that large doses of inhaled corticosteriods (Fluticasone 1000mcg daily) have reduced median exacerbation rate in patients with severe COPD by $25 \% .^{8}$

The current audit has been able to show the reduction of total inhaled corticosteriods over the study period. The number of patients using inhaled corticosteriods declined from $70 \%$ in January 1999 to $53 \%$ in January 2001. Also patients taking more than $800 \mathrm{mcg}$ daily inhaled corticosteriods had reduced from $50 \%$ to just under $10 \%$ over the audit period of three years. However, inhaled corticosteriods were not withdrawn in patients with severe COPD.

Stopping smoking can reduce the rate of decline in lung function in most COPD patients who smoke and can increase the quality of life. ${ }^{9}$ Hence smoking cessation is an essential part of COPD management. The current study shows a considerable reduction in the percentage of smokers from $50 \%$ to $24 \%$ at the end of the audit period. This was confirmed by carbon monoxide (CO) monitoring in these patients. The $\mathrm{CO}$ monitoring results in January 2001 shows $67 \%$ of cessation of smoking. $11 \%$ of patients showed the range of 3.1 to $5 \%$ indicating a considerable reduction in smoking. $5 \%(\mathrm{n}=2)$ of our patients declined the Part of these changes are due to the constant change in our practice population. e.g. smokers and non-smokers joining and leaving the area or dying.

Ashok Deshpande

General Practitioner

\section{Janet Caira}

General Practitioner

Correspondence to:

Wood Lane Surgery

39 Wood Lane

Elm Park

Hornchurch

Essex

RM12 4NS

Tel: $+44(0) 1708450902$

Fax: $+44(0) 1708470875$

E-mail:

ashok.deshpande@gp-

f82028.nhs.uk

Prim Care Resp J 2003; 12(2):58-60

Quality of life of these COPD patients were monitored by assessing their SGRIQ (St George's Respiratory Impact Questionnaire). The current audit shows the increase of percentages of patients whose symptoms were better, rose from $35 \%(n=17)$ to $57 \%(n=21)$ at the end of the third audit cycle. The improvement in quality of life was demonstrated in spite of reduction in inhaled corticosteriods. However, reduction in smoking or stopping smoking altogether was a most important factor in improving the SGRIQ score. The current audit results again emphasise the important role of a specialist nurse advisor in the management of COPD. Nurse intervention establishes better communication with patients and also helps with assessments in spirometry, SGRIQ and appropriate medical intervention.

\section{Conclusion}

The future of the respiratory care depends upon multidisciplinary team approach with shared protocols across primary and secondary care interface. Smoking cessation is the cornerstone of COPD management and COPD patients had CO range of $0-3 \%$ indicating the test. The remaining $5 \%(\mathrm{n}=2)$ showed negative results.

Accurate diagnosis and regular measurement of pulmonary functions of COPD patients helps to assess the appropriate management of these patients. Active involvement of specialist respiratory nurse in primary care will considerably improve the outcome of COPD management. The use of inhaled corticosteriods should be reserved for more severe COPD patients and who have frequent exacerbations.

Conflict of interest: None declared.

\section{Acknowledgements:}

I would like to thank Practice Nurse Teresa Hooper and secretary Mrs Maureen Murphy for their contributions. This audit was supported by 'COPD Response' in providing a specialist respiratory nurse.

\section{References:}

1. COPD Guidelines Group of the Standards of Care Committee of the British Thoracic Society. BTS Guidelines for the Management of Chronic Obstructive Pulmonary Disease. Thorax 1997; 52(supp15):S1-28

2. Chen JC, Mannino DM. Worldwide Epidemiology of Chronic Obstructive Pulmonary Disease. Curr Opin Pulm Med 1999; 5:93-9.

3. Paunels RA et al, Global Strategy for the Diagnosis, Management and Prevention of Chronic Obstructive Pulmonary Disease. Am J Respir Crit Care Med 2001; 163:1256-76.

4. Belman MJ et al. Inhaled bronchodilators reduce dynamic hyperinflation during exercise in patients with Chronic Obstructive Pulmonary Disease. Am J Respir Crit Care Med 1996; 153:967-75. this prevents the disease progression.
5. Sestini et al. Short-acting beta 2 agonists for stable COPD (Chochrane Review). In: Cochrane Library, Issue 4, 2001. Oxford : Update Software.

6. Paggiaro PL et al. Multi-centre randomised placebo-controlled trial of inhaled Fluticasone propionate in patients with Chronic Obstructive Pulmonary Disease: Lancet 1998: 351:773-80.

7. Paunels RA et al. Long term treatment with inhaled Budesonide in persons with Mild cCronic Plmonary Disease who continue smoking. N Engl J Med 1999; 343:1902-9.

8. ISOLDE study investigators. Randomised, double blind, placebo controlled study of Fluticasone propionate in patients with moderate to severe chronic obstructive pulmonary disease: the ISOLDE trial. $B M J$ 2000:320:1297-303.

9. Pelkonen $\mathrm{M}$ et al. Smoking cessation, decline in pulmonary function and total mortality : a 30 year follow-up study among the Finnish cohorts of the Seven Countries Study. Thorax 2001; 56:703-7. 